\title{
Experimental research made during a city cycle on the feasibility of electrically charged SI engines
}

Topical Issue: AMMA 2013

\author{
Levente B. Kocsis $^{1 *}$, Nicolae Burnete ${ }^{1}$ \\ 1 Automotive Engineering and Transport Department, Technical University of Cluj-Napoca, Romania
}

Received 08 October 2013 ; accepted 28 January 2014

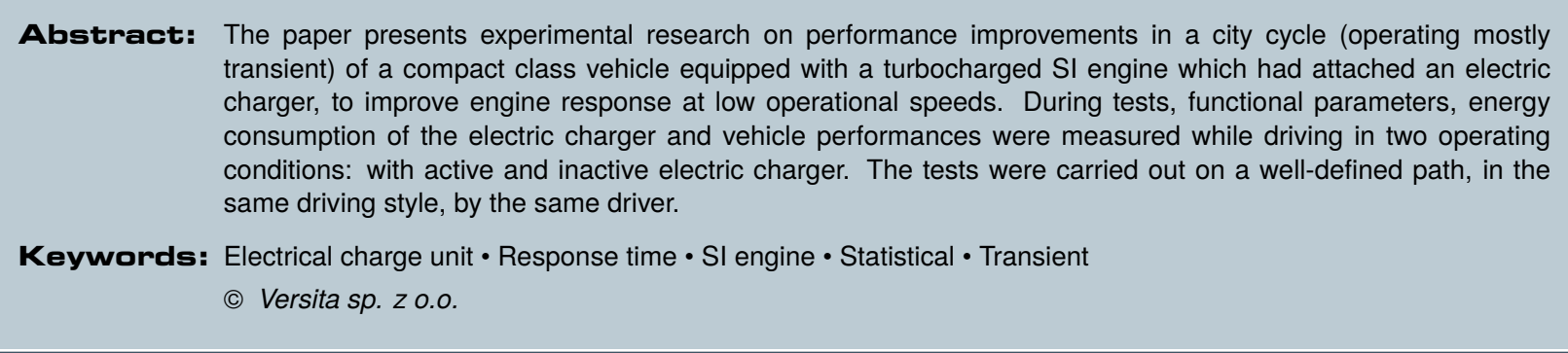

\section{Introduction}

Internal combustion engine charging is a long-debated topic and studied in depth, with many references in scientific literature, yet there are several primary goals that have not been achieved, but due to restrictions placed by pollution standards respectively carbon dioxide emissions reduction imposed by law, the use of turbochargers experienced a very wide spread.

Traditionally, research and studies related to the operation of internal combustion engines have focused on steady-state conditions, paying minor attention to transient operation, although most transport cycle involves Frequent use of the later.

Transient operation is characterized by rapid changes in operating conditions, which may prove to be major

*E-mail: leventekocsis@yahoo.com challenges in terms of engine response [1, 2]. During transient operation, the engine control system must respond to a myriad of different requirements versus steady-state operation, drivability playing the most important role [3].

The fundamental aspect of the transient operation is based on the differences as compared to steady-state operation. In stable operating conditions, engine speed and the amount of injected fuel remains constant, directly influencing the engine's operating parameters and the turbocharger (practically constant as well), but in transient operating conditions engine speed and the amount of injected fuel change, leading to changes in the thermodynamic potential of the exhaust gases, affecting the air flow rate and air pressure supplied by the charging device.

Due to dynamic factors (thermal inertia and fluid inertia in the system), generated mostly by the working principle and dynamic moment of inertia of the turbocharger, the amount of supplied air, required for the complete 
combustion of the injected fuel is delayed, affecting torque build-up and emissions. The most important issue in the study of transient operation of turbocharged engine is the turbocharger delay (turbo-lag) [1, 4].

For a few years now, this issue is addressed through electric turbo-compounding systems, which attracts more attention in recent years with the advance of electronic control devices. Mainly, there are three kinds of electric turbo-compounding systems for internal combustion engines: one type has an electric-assisted turbocharger, the other has a turbo-generator that is in series with the turbocharger, and a third system has a turbo-generator that is in parallel with the turbocharger $[5,6]$.

According to Wei W. and Zhuge W., results obtained with GT-DRIVE software used to evaluate the system performance under driving cycles (US06 and FTP75), show that the performance of parallel turbo-generator system is better than those of the other two kinds of systems. The fuel economy improvement of this system is $4.0 \%$ under US06 driving cycle and 1.6\% under FTP75 driving cycle, compared with the original standard SI engine [7].

Similar results were obtained by Millo F., Mallamo F. and Pautasso E., who conducted research on a city bus equipped with a light truck Diesel engine with attached electrical turbo-compounding system. Among their findings were the substantial improvements during acceleration transients that can be achieved with this system as well as a fuel consumption reduction from $1.5 \%$ to $5.5 \%$ depending on the driving cycle $[8,9]$.

\section{Aims of research}

The main objective of this paper is to highlight the performance improvements brought by the use of an associated electric charger to a turbocharged SI engine in a city cycle (mostly transient).

\section{Material and method}

Ambient temperature values ranged between 8 and $12^{\circ} \mathrm{C}$, the barometric pressure between 0.98 and 1.05 bar. Necessary compensation for the engine to simulate operation under standard atmospheric conditions was made by the ECU. Experimental research was made on a turbocharged SI engine, to which an electrically driven CPT VTES charger was adapted [10].

Functional parameters, consumed energy and performance of the vehicle while on city cycle were measured in two ways: with active and passive electric charger. For this a specific research methodology had to be applied, in order to be able to draw pertinent conclusions (Figure 1).

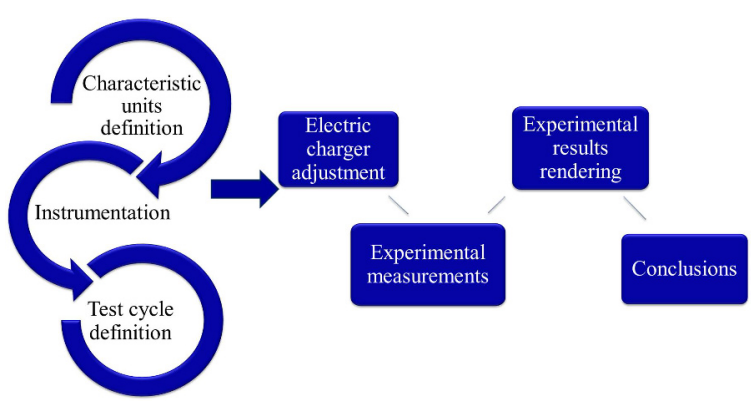

Figure 1. Research methodology.

Experimental vehicle was fitted a spark ignition turbocharged engine with a displacement of $1598 \mathrm{~cm}^{3}$, an engine designed to equip compact and medium sized vehicles. The current engine version is already an improved one, having attached a twin-scroll turbocharger, which contributes substantially to achieve the performances presented in Table 1, where one can find the main general characteristics of the engine.

Electrically charging unit operates at an engine speed range of between 800 and $4000 \mathrm{rpm}$, at engine loads in excess of $25 \%$. The electric charger has a radial design so that optimal working points are the same as the optimal working points of the electric motor. Compressor rotor has a curved blade design, which extends the useful area of the compressor diagram, enabling high efficiency operation over a wide range, as shown by Watson and Janota [11]. The performance characteristics of the electric charger are given in Table 2 [10].

To be able to measure the performance of the vehicle, the electric charger was connected to the CAN network, which communicates with the vehicle's ECU. Open ECU module (RPEMS) was wired in series with ECU of the vehicle, after which it was connected to a computer station to access the operating parameters of the vehicle's powertrain. On the power supply cord between the electric charger and the battery pack a current clamp was placed to read the current through the conductor (the current consumption of electric charger).

Analog output signal of the current clamp was converted into digital signal by an analog-digital converter, signal then processed by a computer station. 
Table 1. Main parameters of the IC engine.

\begin{tabular}{lll}
\hline Parameter & Value and measurement unit \\
\hline Bore & $77.00 \mathrm{~mm}$ \\
Stroke & $85.80 \mathrm{~mm}$ \\
Number of cylinders & 4 in line \\
Displacement & $1598 \mathrm{~cm}^{3}$ \\
Compression ratio & $10.5: 1$ \\
Power & $160 \mathrm{~kW} / 6000 \mathrm{rpm}$ \\
Torque & $305 \mathrm{Nm} / 1600 \mathrm{rpm}$ & Test engine \\
\hline
\end{tabular}

Table 2. Main parameters of VTES charging unit.

\begin{tabular}{ll}
\hline Parameter & Value and measurement unit \\
\hline Maximum pressure ratio & 1.47 \\
Mximum airflow & $500 \mathrm{~kg} / \mathrm{h}$ \\
Maximum speed & $70.000 \mathrm{rpm}$ \\
Time to maximum speed & $<350 \mathrm{~ms}$ \\
Peak shaft power & $4.8 \mathrm{~kW}$ \\
Current draw - Idle & $2.8 \mathrm{~A}$ \\
Current draw - Acceleration & $460 \mathrm{~A}$ \\
Current draw - steady-state & $250 \mathrm{~A}$ \\
Operating temperatures & $-40 \mathrm{la}+125^{\circ} \mathrm{C}$ \\
\hline
\end{tabular}

\section{Results}

City cycle tests were conducted in order to define the benefits of an electrically assisted turbocharged engine in city specific operating conditions (Figure 2 and Figure 3). Tests were made on a definite route with a duration time between 900 and 1000 sec., which contained both busy sections with many intersections and streets with low visibility as well as sections with maximum legal speed of $60 \mathrm{~km} / \mathrm{h}$. Tests were made in the same driving style, by the same driver.

Closely observed parameters were the difference in the mean throttle position between the two versions, engine speed, the developed torque and the gear changes, when the engine is running only with its own turbocharger and with active electrical charger as well.

During these measurements among the continuously monitored values were the current draw of the electric charger and the voltage across the device. Based on these data, the energy consumed by the electric charger during the route was calculated, while Figure 2 and Figure 3 presents the variation of main parameters studied in these tests. Two significant moments were depicted from both city cycles, to highlight the transient benefits of electrically assisted charging versus standard turbocharging. As one can observe from Figure 4, developed torque has a different shape when assisted charging is applied. The two diagrams show a "TIP IN" event occurring in the same gear, at the same engine speed, with approximately the same pedal handling.

When "TIP IN" event occurs, the electric charger mounted in parallel with the standard one creates pressure within less than $0.35 \mathrm{sec}$ and boosts up the whole system's pressure, so that torque is built-up faster, as seen in Figure 5. After $1 \mathrm{sec}$ following the "TIP IN", pressure in the intake of the electrically charged engine is roughly double than that in the standard engine's intake.

Following these observations, in order to make objective conclusions, a statistical analysis of main parameters was performed, examining particularly the engine speed, frequency of gears used and engine load during these measurements. To achieve this, from the total of measured values (with a frequency of $100 \mathrm{~Hz}$ ) were extracted those intervals where the speed was zero, and the engine speed was idle speed.

The frequency of incidence for engine speed domains that were analyzed for two cases (Figure 6): operation with standard turbo engine, respectively engine equipped with electric charger. Basically it was determined how long the engine speed was between predefined valuesby counting values between these speeds.

The first examined area has no interest on engine 


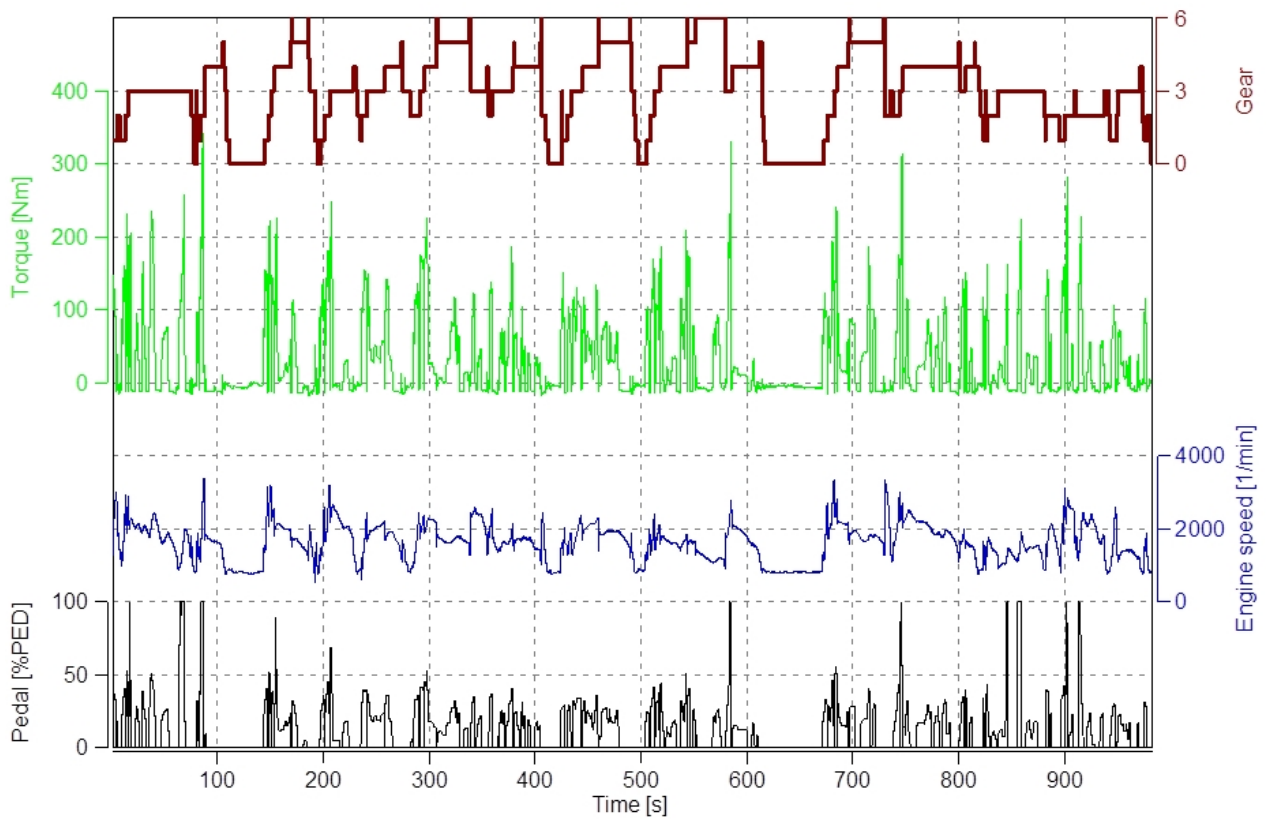

Figure 2. City cycle without VTES.

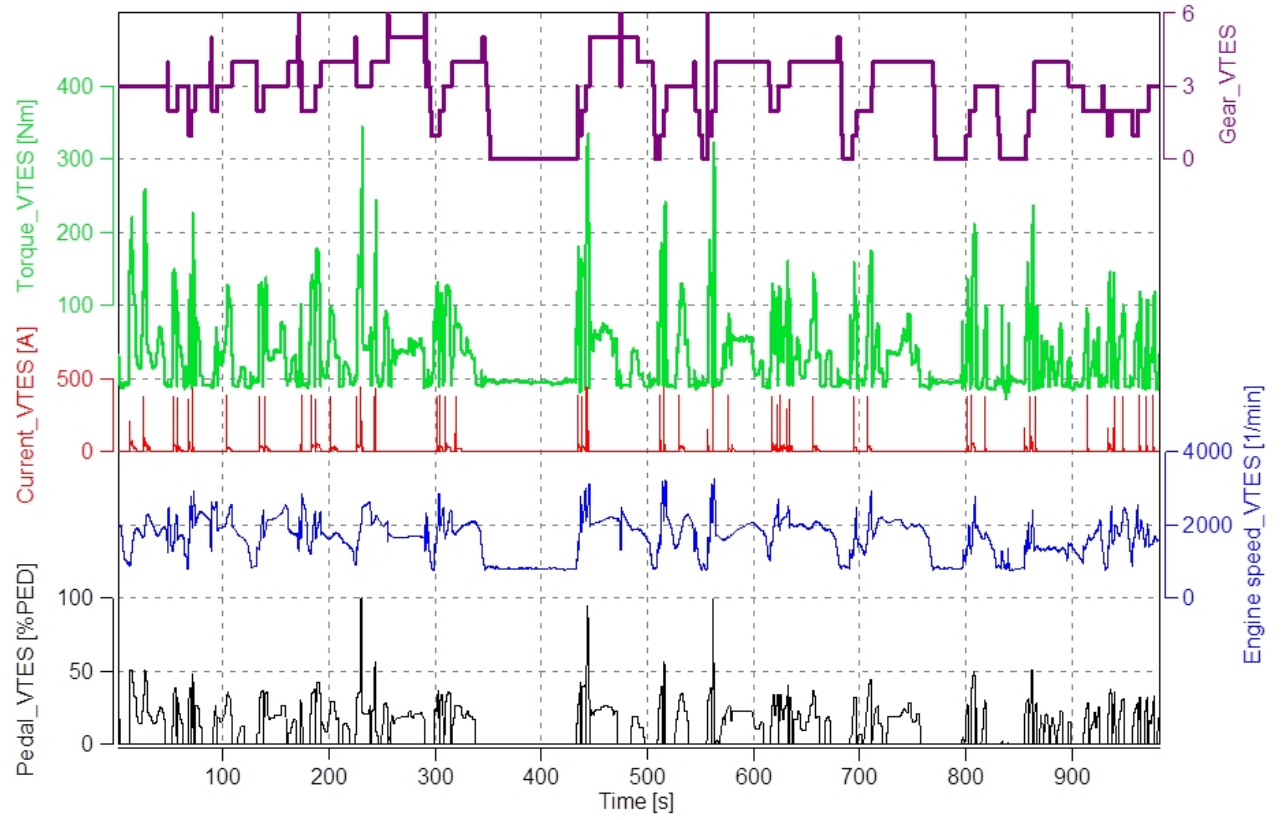

Figure 3. City cycle with active VTES. 

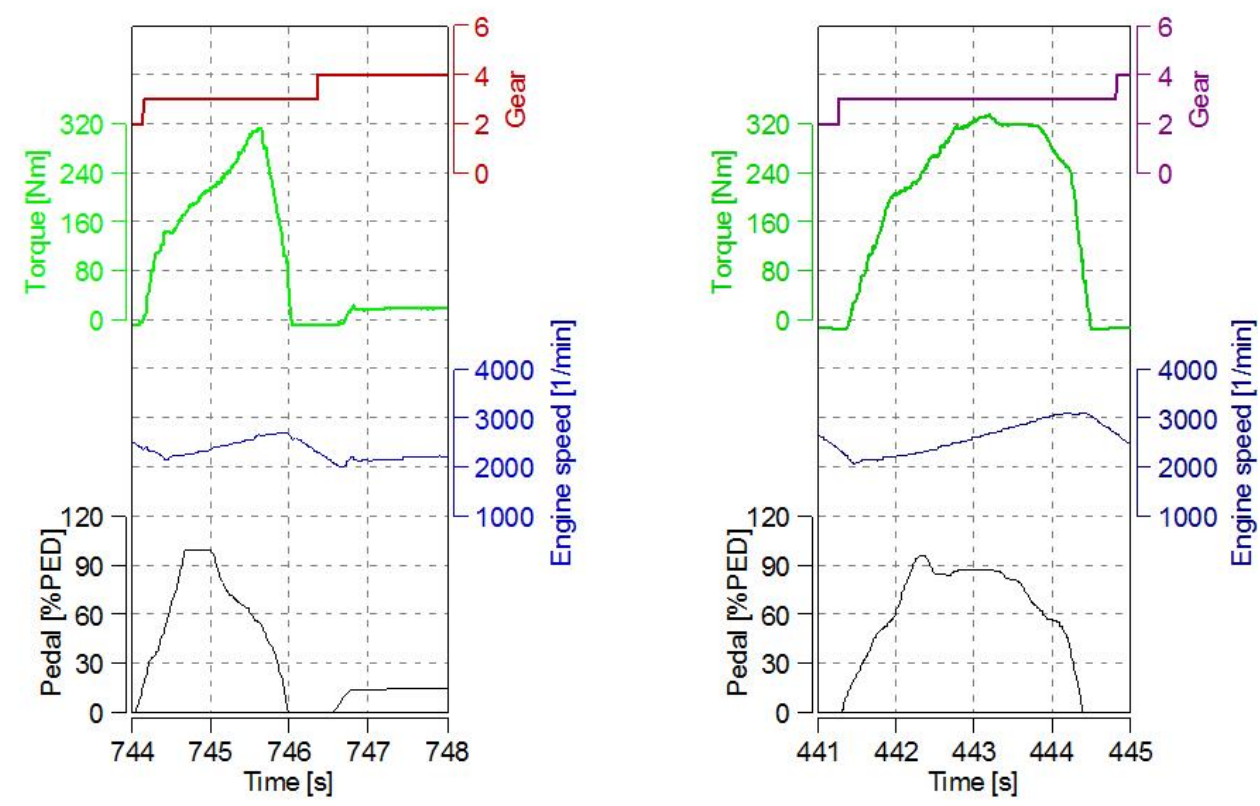

Figure 4. TIP IN event without and with active VTES.

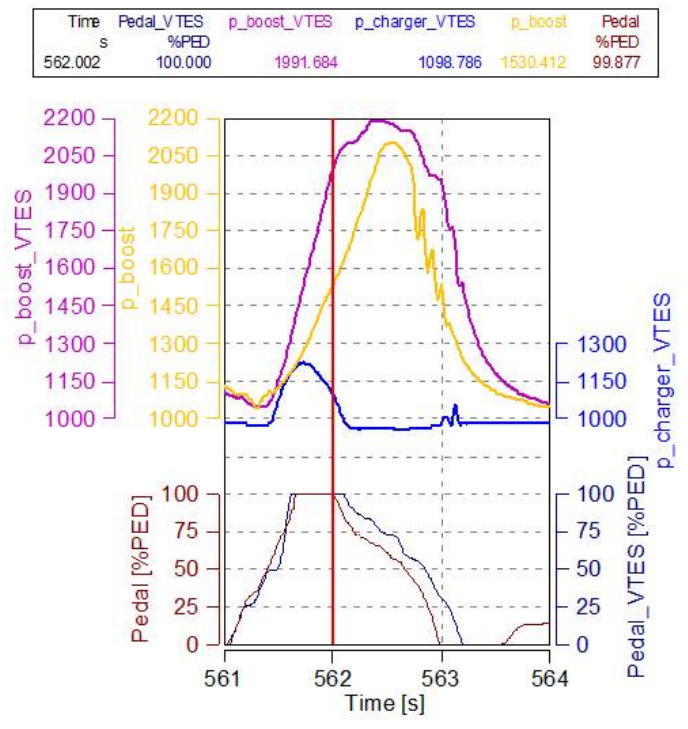

5a.)

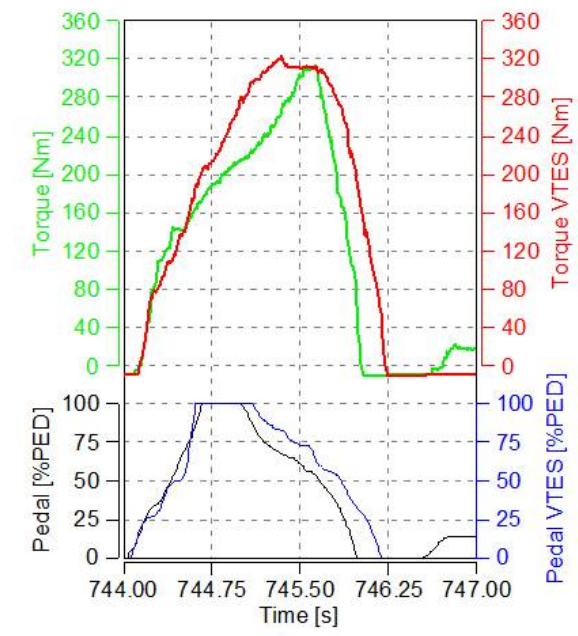

5b.)

Figure 5. Pressure and torque build-up at a "TIP IN" event. 


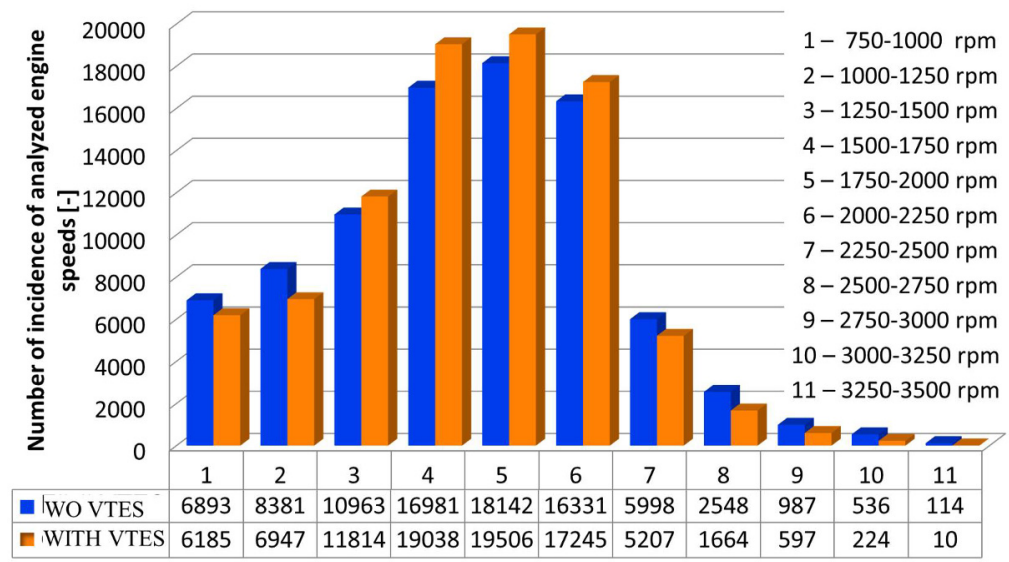

Figure 6. Frequency incidence of analyzed engine speeds.

performance; the engine idle speed is included here. The second domain requires explanation. Somewhat contrary to expectations, standard equipped engine worked longer in this area $(1000 \div 1250 \mathrm{rpm})$. This may be in part due to differences in traffic (which could not be $100 \%$ similar), but may be in part due to the fact that at very low speeds, the pressure in the combustion chamber increased for the version equipped with electric charger, resulting in high vibrations, which have prevented the use of this domain. From engine speed of $1250 \mathrm{rpm}$, situation changes, the engine equipped with the electric charger being used more in the range of speeds between 1250 and $2250 \mathrm{rpm}$, than its counterpart equipped with standard turbocharger.

Engine with standard turbo was more frequently used than the version equipped with electrical charger in speed range exceeding $2250 \mathrm{rpm}$. If in the case of the standard version, engine throttled beyond $3000 \mathrm{rpm}$ was used $0.736 \%$ of the city cycle, for the engine equipped with the electric charger this was only $0.265 \%$, while the average developed torque over the entire test cycle had a difference of only one-tenth of a unit. This improvement was due to higher torque from very low engine speeds, which provided more security to the driver. It has to be noted that the tests were carried out in the order mentioned above. Conversely difference between the analyzed parameters would be higher.

It is interesting to note that during this city cycle the engine equipped with the electrically assisted charger was used in a proportion of $84.4 \%$ in the speed range between 1000 and $2250 \mathrm{rpm}$. Following a detailed analysis of the measured data a slight reduction in average engine speed at which the engine operated during the test

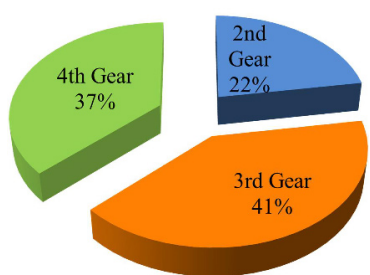

a)

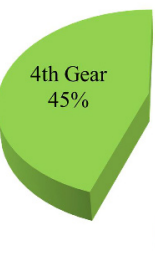

b)

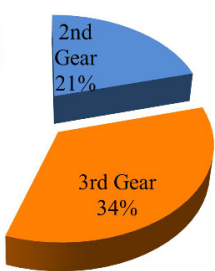

Figure 7. Comparative share of gear use: a) unassisted version and b) electrically assisted.

was reported, which projects lower fuel consumption, especially by reducing frictional losses associated with the new operating conditions. It can also be seen the lower percentage of use of the third gear $(41 \%$ to $34 \%)$ and the increased percentage in the use of fourth gear (from $37 \%$ to $45 \%$ ) for the electrically assisted solution (Figure 7), given that the difference between average speeds to the whole city cycle is neglectable (40.81 to $40.76 \mathrm{~km} / \mathrm{h}$ average speed for electrically charged version). This is explained by developing torque on a wider range of speeds.

Comparing the results of engine load was another instrument that has demonstrated the benefits of the solution with electrically assisted turbocharging. According to Figure 8 and Figure 9 engine load in two versions (standard equipped engine and engine equipped with electric charger) varies significantly during the city cycle. 


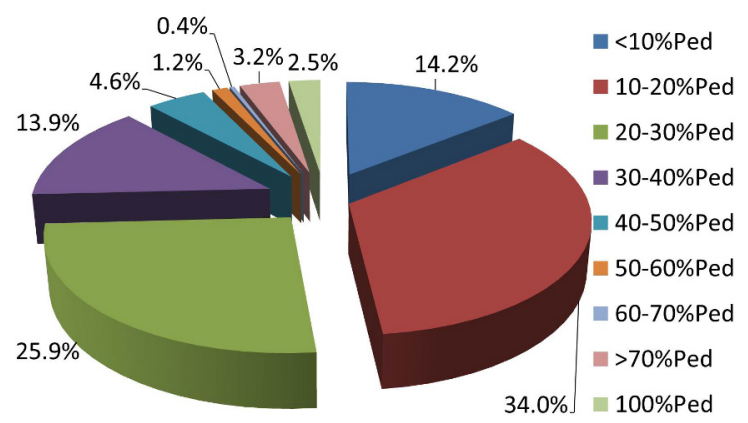

Figure 8. Throttle domain diagram for the standard engine.

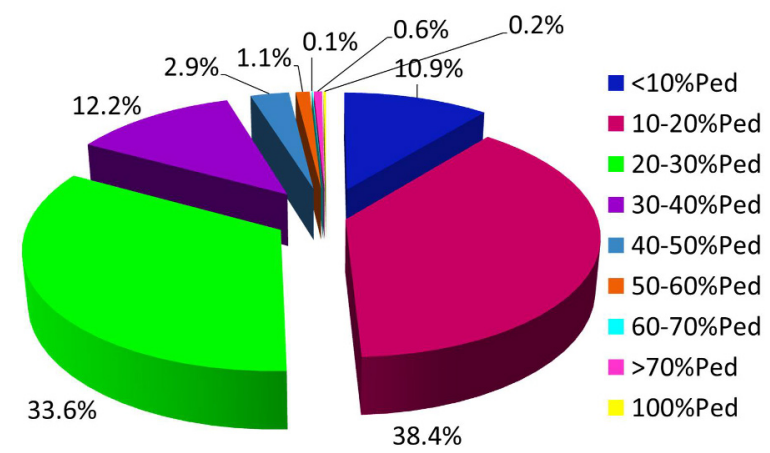

Figure 9. Throttle domain diagram for the electrically charged engine.

The engine equipped with electric charger operated predominantly between 10 to $30 \%$ throttle $(72 \%$ of the route being covered with throttle values in this field) and only $4.9 \%$ of the route being covered with throttle values exceeding $40 \%$. Standard fitted engine on the other hand operates more at very small loads $(<10 \%$, which is not efficient) and with throttle values exceeding $40 \%(11.9 \%$ of the route).

The greatest difference was obtained (just as in the case of engine speeds) at operation with loads greater than $70 \%$, where the difference is an order of magnitude $(2.5 \%$ to $0.2 \%$ standard-equipped version versus the version equipped with electric charger).

Analyzing these results, a tendency to work with throttling values between 10 and $40 \%$ for the version equipped with electric charger, thus avoiding the very small throttle values (uneconomical domain due to high friction losses relative to the developed power) and the high throttle domain (uneconomical due to mixture enrichment needed to protect the turbocharger from excessive heat) can be seen.

\section{Conclusion}

After experimental research was carried out, the following views and assessments were formulated on the feasibility of electrically charged SI engines in urban cycle:

- The upper limit of electrically assisted charging of $6 \mathrm{sec}$. during an event is sometimes too low, leaving room for optimization.

- Current consumption of the electric charger is very high, but taking into consideration the short periods it is used, did not overload the battery pack with which the vehicle was equipped.

- Statistical analysis of city cycles show less acceleration with WOT (Wide Open Throttle) and average engine speed is also lower for the electrically assisted version, and this projects future fuel economy.

- Generating $123.5 \mathrm{~kJ}$ of energy to drive the electric charger requires 0.027 litres of petrol. The engine provides superior performance and the possibility of fuel saving. Having good elasticity suggests driving with lower engine speeds.

\section{Acknowledgement}

Research work was made possible with the support of AVL List $\mathrm{GmbH}$, with special thanks to Mrs. Barbara Walluschek and Ing. Kurt Prevedel.

\section{References}

[1] Rakapoulos D. C., Evangelos G. G., Diesel Engine Transient Operation. Principles of Operation and Simulation Analysis, Springer Verlag, London, 2009

[2] Heywood, J. B., Internal combustion engine fundamentals, New York, McGraw-Hill, 1988

[3] Zellbeck H., Friedrich J., Berger C., Electrically assisted turbocharging as a new boosting concept, MTZ nr. 60, 1999

[4] Burnete N., ş.a., Construcţia şi calculul motoarelor cu ardere internă (Mecanismul motor), Editura Todesco, Cluj-Napoca, 2001, ISBN 973-8198-17-8 
[5] Balis C., Middlemass C., Shaded S. M., Design \& development of E-turbo for suv and light truck application, proceedings of Deer 2003: Diesel Engine Emissions Reduction Conference Newport, RI, August 24-28

[6] Vuk C. T., Electric turbo-compounding - A technology whose time has come, Proceeding of DEER 2005: Diesel Engine Emissions Reduction Conference, Chicago, Illinois, August 21-25

[7] Wei W., Zhuge W., Zhang Y., He Y., Comparative study on electric turbo-compounding systems for gasoline engine exhaust energy recovery, Proceeding of the ASME Turbo Expo 2010: Power for Land, Sea, and Air, GT 2010; Glasgow; United Kingdom; 14 June 2010 through 18 June 2010; Code 87468

[8] Millo F., Mallamo F., Pautasso E., Giano Mego, G.,
The potential of electric exhaust gas turbocharging for HD Diesel engines, SAE Paper

[9] Hopmann U., Algrain M. C., Diesel engine electric turbo compound technology, SAE Paper 2003-012294, 2006-01-0437

[10] Criddle M., Documentation zum Programmstand RPEMS_Future12_CPT, CPT, 2011

[11] Watson N., Janota M., Turbocharging the Internal Combustion Engine, The Macmillan Press Ltd, Houndmills, 1982

[12] Criddle M., Morris G., Cutts K., Fraser D., Morgan G., Entwicklung der nächsten Generation von elektrischen Auflagesystemen für Pkw-Anwendungen, Aachener Kolloquium Fahrzeug- und Motorentechnik, Aachen, 2005 